\title{
Multifocality and multicentricity are not contraindications for sentinel lymph node biopsy in breast cancer surgery
} Alberta Ferrari*1, Paolo Dionigi ${ }^{4}$, Francesca Rovera ${ }^{1}$, Luigi Boni ${ }^{1}$, Giorgio Limonta ${ }^{1}$, Silvana Garancini², Diego De Palma ${ }^{2}$, Gianlorenzo Dionigi ${ }^{1}$, Cristiana Vanoli ${ }^{3}$, Mario Diurni ${ }^{1}$, Giulio Carcano ${ }^{1}$ and Renzo Dionigi ${ }^{1}$

Address: ${ }^{1}$ Department of Surgical Sciences, University of Insubria, Varese, Italy, ${ }^{2}$ Department of Nuclear Medicine, University of Insubria, Varese, Italy, ${ }^{3}$ Department of Radiology, University of Insubria, Varese, Italy and ${ }^{4}$ Dipartimento di Scienze Chirurgiche, Rianimatorie-riabilitative e dei Trapianti d'Organo, University of Pavia, Fondazione IRCCS Policlinico San Matteo, Pavia, Italy

Email: Alberta Ferrari* - albertaferrari@libero.it; Paolo Dionigi - p.dionigi@smatteo.pv.it; Francesca Rovera - francesca.rovera@uninsubria.it; Luigi Boni - luigi.boni@uninsubria.it; Giorgio Limonta - g.limonta@libero.it; Silvana Garancini - gianlorenzo.dionigi@uninsubria.it; Diego De Palma - luigi.boni@uninsubria.it; Gianlorenzo Dionigi - gianlorenzo.dionigi@uninsubria.it; Cristiana Vanoli - albertaferrari@libero.it; Mario Diurni - mdiurni@yahoo.com; Giulio Carcano - giulio.carcano@uninsubria.it; Renzo Dionigi - renzo.dionigi@uninsubria.it

* Corresponding author

Published: 20 November 2006

World Journal of Surgical Oncology 2006, 4:79 doi:10.1186/1477-7819-4-79

This article is available from: http://www.wjso.com/content/4/I/79

(c) 2006 Ferrari et al; licensee BioMed Central Ltd.

This is an Open Access article distributed under the terms of the Creative Commons Attribution License (http://creativecommons.org/licenses/by/2.0), which permits unrestricted use, distribution, and reproduction in any medium, provided the original work is properly cited.
Received: 17 May 2006

Accepted: 20 November 2006

\begin{abstract}
Background: After the availability of the results of validation studies, the sentinel lymph node biopsy (SLNB) has replaced routine axillary dissection (AD) as the new standard of care in early unifocal breast cancers. Multifocal (MF) and multicentric (MC) tumors have been considered a contraindication for this technique due to the possible incidence of a higher false-negative rate. This prospective study evaluates the lymphatic drainage from different tumoral foci of the breast and assesses the accuracy of SLNB in MF-MC breast cancer.

Patients and methods: Patients with preoperative diagnosis of MF or MC infiltrating and clinically nodenegative (cN0) breast carcinoma were enrolled in this study. Two consecutive groups of patients underwent SLN mapping using a different site of injection of the radioisotope tracer: a) "2ID" Group received two intradermal (ID) injections over the site of the two dominant neoplastic nodules. A lymphoscintigraphic study was performed after each injection to evaluate the route of lymphatic spreading from different sites of the breast. b) "A" Group had periareolar $(A)$ injection followed by a conventional lymphoscintigraphy. At surgery, both radioguided SLNB (with frozen section exam) and subsequent $A D$ were planned, regardless the SLN status.

Results: A total 31 patients with MF $(n=12)$ or $M C(n=19)$ invasive, $c N 0$ cancer of the breast fulfil the selection criteria. In 2 ID Group $(n=15)$ the lymphoscintigraphic study showed the lymphatic pathways from two different sites of the breast which converged into one major lymphatic trunk affering to the same SLN(s) in 14 (93.3\%) cases. In one (6.7\%) MC cancer two different pathways were found, each of them affering to a different SLN. In A Group $(n=16)$ lymphoscintigraphy showed one $(93.7 \%)$ or two $(6.3 \%)$ lymphatic channels, each connecting areola with one or more SLN(s). Identification rate of SLN was 100\% in both Groups. Accuracy of frozen section exam on SLN was $96.8 \%$ (I case of micrometastasis was missed). SLN was positive in 13 (4I.9\%) of 3I patients, including 4 cases $(30.7 \%)$ of micrometastasis. In 7 of $13(53.8 \%)$ patients the SLN was the only site of axillary metastasis. SLNB accuracy was $96.8 \%$ (30 of 31 ), sensitivity 92.8 (I3 of I4), and false-negative rate $7.1 \%$ (I of I4).
\end{abstract}


Since the case of skip metastasis was identified by the surgeon intraoperatively, it would have been no impact in the clinical practice.

Conclusion: Our lymphoscintigraphic study shows that axillary SLN represents the whole breast regardless of tumor location within the parenchyma. The high accuracy of SLNB in MF and MC breast cancer demonstrates, according with the results of other series published in the literature, that both MF and MC tumors do not represent a contraindication for SLNB anymore.

\section{Background}

During the last few years world-wide consensus has been obtained for SLNB as new standard of axillary staging in early breast cancer. According to the International Consensus Conference on SLNB (Philadelphia, 2001) [1] the technique is indicated for unifocal, infiltrating and clinically node-negative breast carcinoma up to $3 \mathrm{~cm}$ in diameter. Absolute or relative contraindications include pregnancy, tumors downstaged by neoadjuvant chemotherapy, previous breast or axillary surgery, some cases of multifocality (once total diameter of the breast quadrant involved by cancer is greater than 3 or $5 \mathrm{~cm}$ ) and multicentricity [1].

Recently, both European and United States guidelines on breast cancer treatment have included SLNB as first choice option for early infiltrating, unifocal and clinically nodenegative lesions, providing that such procedure is performed by experienced surgeons [2-4]. However, several limits for application of this technique have been recently revised [5] in order to extend the potential benefit of avoiding unnecessary axillary dissection. The role of SLNB in multifocal (MF) and multicentric (MC) breast cancer is one of the most common topic open to debate.

Although the terms MF and MC have often been used to identify the same condition, $\mathrm{MC}$ cancer should be defined as multiple synchronous tumors originating in different sites of the breast, and MF cancer as multiple foci of the same tumor.

Over the past few years, several clinical and anatomical criteria have been proposed to identify MF and MC cancers, including the distance between cancer, foci (greater than 2, 3 or $5 \mathrm{~cm}$ in $\mathrm{MC}$ cancer), the presence of histologically normal tissue among nodules $(\mathrm{MC})$, the location in the same (MF) or different (MC) quadrants of the breast $[6,7]$.

During early diffusion of the SLNB technique the main theory of lymphatic drainage of the breast postulated the presence of multiple pathways connecting different sites of the breast to different SLNs. As consequence, both MF and $\mathrm{MC}$ breast cancers were considered relative (MF) or absolute (MC) contraindications to SLNB [1] due to concerns about the possibility to identify the "true" SLN.
Moreover, earlier results of validation studies on SLNB technique suggested the possible incidence of a higher false-negative rate in MF and MC cancers [8]. Nevertheless, recent studies support now a different theory about breast lymphatic drainage: the SLN (one or more SLNs) would be representative of the whole breast, considered as a single limphatic unit $[9,10]$. In this case, SLNB technique in $\mathrm{MF}$ and $\mathrm{MC}$ cancers should be as accurate as in unifocal breast tumors [11].

This prospective study was designed to evaluate the lymphatic drainage from different tumoral foci of the breast and to assess the accuracy of the SLNB in MF and MC invasive breast cancers.

\section{Patients and methods}

Patients with preoperative diagnosis of MF or MC breast carcinoma were prospectively enrolled in this study. Cases of suspicious MF and MC tumors identified after clinical, mammographic and echographic assessment had to be confirmed by positive fine needle aspiration cytology (FNAC) or core biopsy histology in at least two of the nodules; cases with one positive lesion associated with other suspicious nodules with athypical cells on FNAC were also included in the study.

Breast cancer was defined as MF if two or more lesions were located in the same quadrant and distance from each other less than $5 \mathrm{~cm}$. If nodules arises in different quadrants of the breast and/or were distant each other more than $5 \mathrm{~cm}$ the cancer was defined as MC. Exclusion criteria were: ductal or lobular in situ carcinomas, clinical and/or echographic evidence of positive axilla, neoadjuvant chemotherapy, previous breast or axillary surgery or radiotherapy. Although tumor size greater than 3 or $5 \mathrm{~cm}$ is considered a contraindication for SLNB in most guidelines, T2-T3 cancers were included in this study due to recent reports of high accuracy of SLNB even in these cases [12].

Written informed consent was required to include patients in this study and approval from the Ethical Committee of the Hospital was obtained.

The day before surgery SLN mapping was performed using the radioisotope technique [13]. All patients were injected 
with $20-40 \mathrm{mBq}$ of 99mTc-nanocolloid $(<100 \mathrm{~nm}$ in diameter), but in two consecutive groups of patients a different site of injection was used. 1) 2ID Group. A former series of patients was designed to receive two consecutive intradermal (2ID) injections of the tracer [14] in the cutaneous projections corresponding to the deep site of each nodule (in patients with more than two nodules, injections were performed over the two dominant lesions most distant to each other). In case of non-palpable tumor the technique of radio-guided localization (ROLL) under ultrasonography (US) or stereotaxis was used. During the procedure, the cutaneous projection of the non-palpable lesions was also marked on the skin in order to guide the intradermal injection of the tracer during SLN mapping.

After each tracer injection a lymphoscintigraphic study was planned to evaluate the route of lymphatic spreading from different sites of the breast. The imaging protocol included: 1) early imaging (after 5 minutes) showing the lymphatic route from the site of injection to the SLN; 2 ) late imaging (after 30 minutes) demonstrating the presence and the number of the SLN(s) identified. Both images were performed with shelded injection site and after positioning of a low activity ${ }^{57} \mathrm{Co}$-flood source in order to obtain the body outline. The lymphoscintigraphic images performed after both the first and the second intradermal injections were then compared in order to recognized if the identified lymphatic route and SLN(s) were coincident or not. 2) A Group. In the subsequent group of women included in this study a periareolar (A) injection technique as described by other authors [15] was used, followed by a preoperative lymphoscintigraphy with early ( 5 minutes) and late (30 minutes) imaging.

Whenever possible, breast surgery was conservative in patients with MF cancer, while, in the remaining cases of $\mathrm{MF}$ and in all MC tumors, formal mastectomy with immediate reconstruction was performed. Axillary surgery consisted in the SLNB performed by radioguided technique, followed by AD. Each hot SLN (lymph nodes with counts of $>10$ times that of the background counts) was excised and immediately examined with consecutive $200 \mu \mathrm{m}$ frozen sections and, regardless from the result of SLN status, routine axillary dissection was performed in all patients.

Definitive histopathological examination was performed on SLNs by routine hematoxylin-eosin staining completed by immunohistochemistry for cytokeratin just in doubtful cases. According to the revised TNM staging system of the American Joint Cancer Commission, the SLN was considered positive when a metastatic focus $>0.2 \mathrm{~mm}$ in diameter was found on frozen sections and/or on definitive histopathology examination.
If preoperative MF or MC invasive breast cancer diagnosis was not confirmed on the surgical specimen examination, patients were excluded from the study.

\section{Results}

Between January 2004 and December 2005, 292 patients underwent breast surgery for cancer at the Department of Surgery of the University of Insubria. Among these women, 35 patients had preoperative diagnosis of infiltrating MF or MC breast carcinoma; 2 cases were excluded from the study due to clinically positive axilla, confirmed by ultrasound.

The remaining 33 patients were enrolled in the study, and other 2 patients were excluded at the definitive pathologic examination, due to a suspected second focus of ductal carcinoma in situ (DCIS) in one patient and atypical ductal hyperplasia $(\mathrm{ADH})$ in the other one.

The remaining 31 patients (all female, mean age $64.1 \pm$ $11.6)$ had confirmed MF $(n=12)$ or $M C(n=19)$ infiltrating cNO breast carcinoma. The first 15 patients of this series received a double intradermal radioisotope injection over the two most distant neoplastic nodules (2ID Group), while the remaining 16 patients underwent periareolar injection (A Group).

\section{Lymphoscintigraphic anatomy}

In the 2ID Group the lymphoscintigraphic study after each injection showed the pattern of lymphatic spreading from two different sites of the breast. In 14 (93.3\%) cases (4 MF, $10 \mathrm{MC}$ ) the (tratto più distale) pathway of diffusion and the affering SLN(s) were common.

As shown in figure 1, the tracer, even when injected in different quadrants of the breast, migrated in the upper outer quadrant were converged into a unique lymphatic channel which terminated in one or more SLN(s). In only one $(6.7 \%)$ case of MC cancer two different dominant pathways were present along the upper outer quadrant of the breast (figure 2), each of them affering to a different SLN.

In the A Group lymphoscintigraphy showed one main lymphatic trunk connecting subareolar plexus to one or more SLN(s) in 15 out of 16 cases (93.7\%), while in one patient two different lymphatic channels started from areola and each one ended separately at a different SLN.

\section{Breast tumors features}

In 31 patients affected by MF $(n=12)$ or MC $(n=19)$ infiltrating breast cancer the number of lesions at preoperative assessment were 2 in 28 cases, 3 in 2 patients and 4 in the remaining one, while histology on surgical specimens revealed 2 lesions in 23 cases, 3 in 6 cases and 4 in 2 cases. Mean diameter of the largest nodule was $23.3 \pm 10.1$ (10 


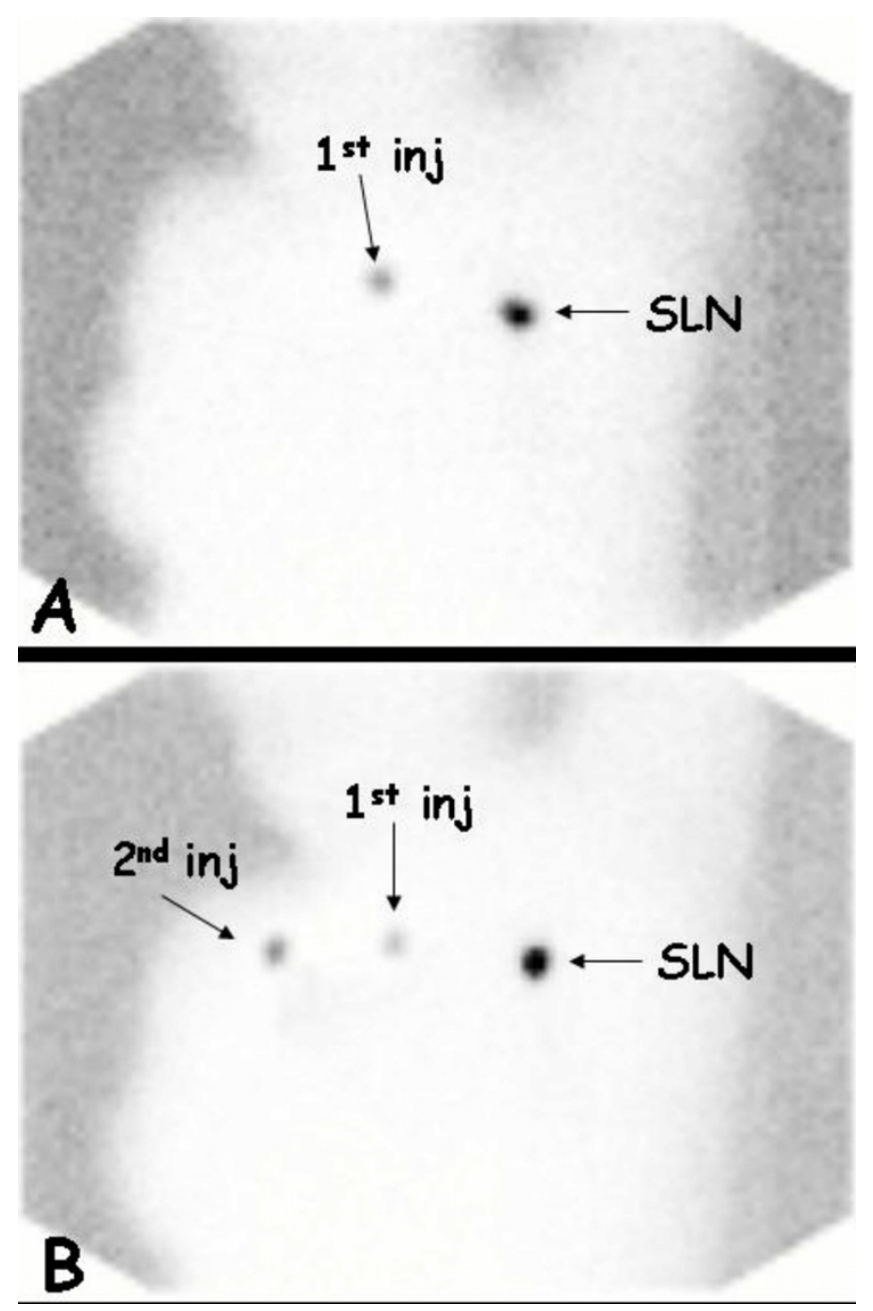

Figure I

Lymphoscintigraphic study performed in a patient affected by invasive MC breast cancer (two nodules located in the upper outer and inner quadrants of the left breast). The patient underwent two subsequent lymphoscintigraphies after each intradermal injection of the tracer over the two neoplastic foci (2ID Group), showing one sentinel lymphatic channel affering to the same SLN. A) First lymphoscintigraphy performed after the first radioisotope injection over the tumoral focus located in the upper outer quadrant of the breast. One SLN is visualized in the axilla. B) Second lymphoscintigraphy performed in the same patient after the second radioisotope injection over the other tumoral focus located in the upper inner quadrant of the breast. The same but hotter SLN is visualized in the axilla.

$\div 60) \mathrm{mm}$. Patients were classified as: T1, T2 and T3 in 15 (48.4\%), 15 (48.4\%) and 1 (3.2\%) cases, respectively.

Breast conserving surgery was performed with radical margins in 8 patients with MF cancer, while the remaining $74.2 \%$ of cases ( $4 \mathrm{MF}$ and all $19 \mathrm{MC}$ tumors) underwent mastectomy with immediate reconstruction (except for 3 patients who refused plastic surgery). After SLNB, three levels $\mathrm{AD}$ was performed in all patients (mean number of lymph nodes excised per patient: $17.9 \pm 6.2$ ).

\section{Accuracy of SLNB in MF-MC tumors}

Using radioisotope technique SLN was identified in all 31 cases (100\% identification rate) in both groups. The mean number of SLNs detected was $2.1 \pm 0.9(1-4)$, without any difference between the 2ID $(2.1 \pm 0.9)$ and A Group (2.06 $\pm 0.9)$. Histology of SLN from frozen sections was confirmed at definitive pathologic exam in all but one patient (96.8\% accuracy rate), in which micrometastasis in the SLN was revealed at definitive histopathological exam alone.

At least one positive SLN was found in 13 (41.9\%) out of 31 patients with MF-MC invasive breast cancer: 9 macrometastases (> $2 \mathrm{~mm}$ in size) and 4 (30.7\%) micrometastases (unique neoplastic focus from 0.2 to $2 \mathrm{~mm}$ in size). No case of isolated tumoral cells (ITC) was detected.

In 7 out of $13(53.8 \%)$ patients with positive SLN (including all 4 cases of micrometastatic SLN), such a node was the only site of metastases. SLN status correctly predicted complete axillary status in 30 out of 31 patients; indeed in one patient with 2 negative SLNs, one positive first level lymph node (metastatic focus measuring $11 \mathrm{~mm}$ in diameter) was demonstrated after complete AD. However, this positive non radioactive lymph node had been already identified by the surgeon as strongly suspicious for skip metastasis [16,17].

Including this case as a false negative (FN) result, the $\mathrm{FN}$ rate was $7.1 \%$ ( 1 out of 14 ), and sensitivity, negative predictive value and accuracy of SLNB in MF-MC invasive breast cancer were $92.8 \%, 94.4 \%$ and $96.8 \%$, respectively.

\section{Discussion}

During the last years the SLNB technique has replaced routine $\mathrm{AD}$ as standard of care for lymph node staging of breast cancer [18]. Excellent accuracy of the technique with low false negative rate is well established in small, unifocal, clinically node-negative tumors, in absence of contraindications such as previous breast or axillary surgery, neoadjuvant chemotherapy, chest-wall irradiation.

To date, SLNB represents a minimally invasive, highly accurate method of axillary staging, which allows almost $65-70 \%$ patients to be spared from $\mathrm{AD}$ and its related morbidity [19]. Patients affected by MF and MC breast carcinoma are excluded from SLNB in most international guidelines, due to concerns about a possible multiple pattern of lymphatic spreading from different neoplastic nodules of the breast. However, searching for the best 


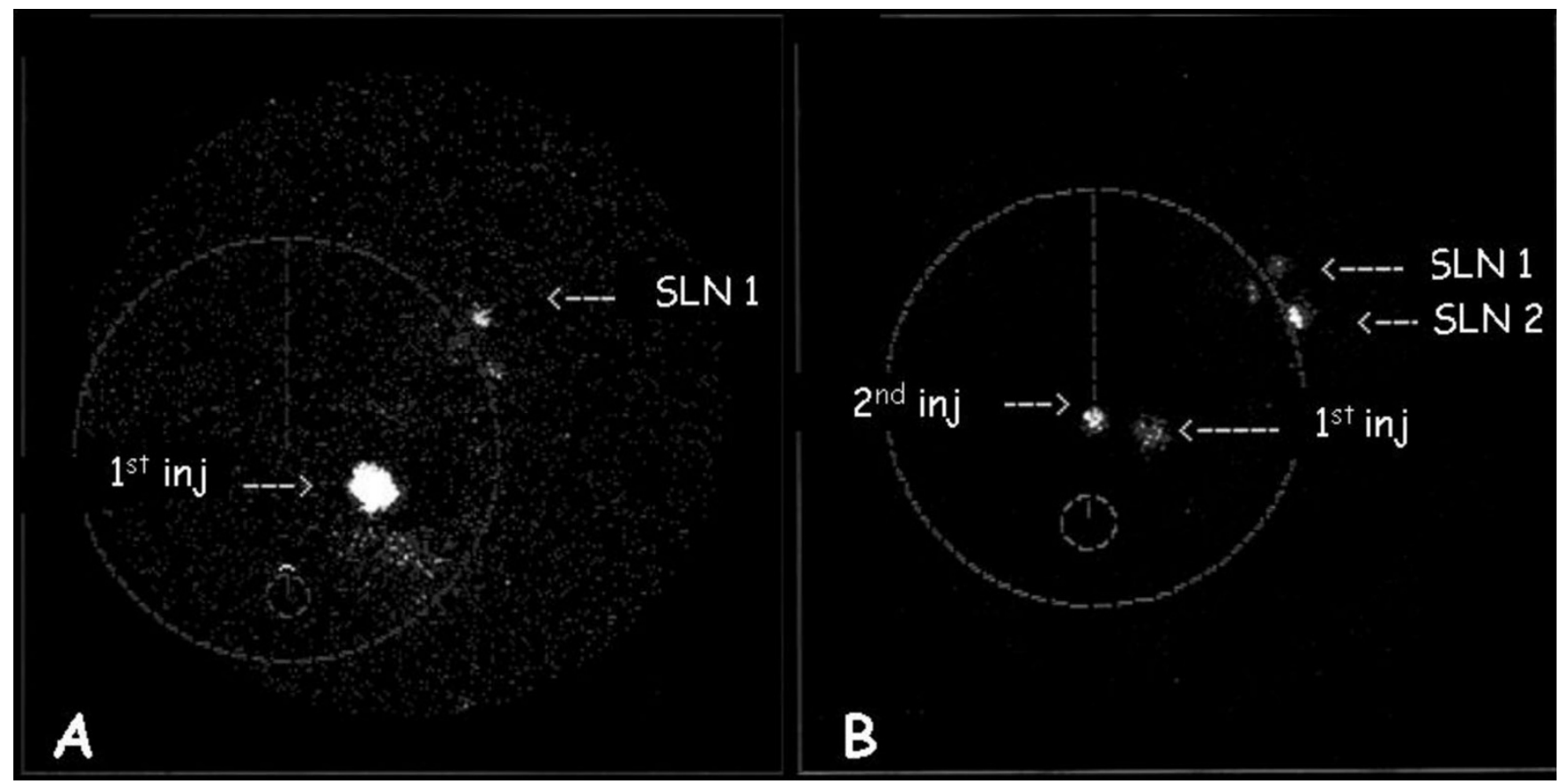

Figure 2

Lymphoscintigraphic study performed in a patient affected by invasive MC breast cancer (two nodules located in the upper outer and inner quadrants of the left breast). The patient underwent two subsequent lymphoscintigraphies after each intradermal injection of the tracer over the two neoplastic foci (2ID Group), showing two sentinel lymphatic channels mainly affering to different SLNs. A) First lymphoscintigraphy performed after the first radioisotope injection over the tumoral focus located in the upper outer quadrant of the breast. One SLN is visualized in the axilla. An other LN shows low radioactivity. B) Second lymphoscintigraphy performed in the same patient after the second radioisotope injection over the other tumoral focus located in the upper inner quadrant of the breast. One different pathway is visualized traversing the outer upper quadrant of the breast, which is mainly connected to the second SLN visualized after the first injection.

technique of SLN mapping stimulated further developments in the field of functional lymphatic anatomy [20].

Historically, under the nipple-areola complex a rich lymphatic network (Sappey plexus) seems to receive the lymph from the whole breast and then drains to the axilla [21], while according to studies from others the lymphatics in the gland are directly connected to the axilla [22]. Although controversies remain about the course of lymph flow between breast parenchyma and axilla, the theory of the breast considered as a single lymphatic unit, at least for what concerns axillary SLN, it is now widely accepted.

The correspondence of lymphatic drainage between the deep glandular and the overlying skin in the same quadrant of the breast has been already demonstrated [23]. Such a "lobary" theory of lymphatic anatomy allowed the diffusion of the intradermal injection of the marker for SLN identification as the best option technique because of the optimal identification rate of SLN $[14,16]$.
More recently, a correspondence between peritumoral and areolar injection has also been demonstrated. Regardless from tumor location within the breast, in over $90 \%$ of cases the periareolar injection technique detects the same SLN(s) which is identified by the peritumoral injection using two different markers (radioisotope and blue dye) $[9,15,24,25]$. Furthermore, also the use of areolar injection techniques as compared to the classical peritumoral provides better results in terms of identification rates of SLN and equal or even better accuracy [26-28].

Lymphoscintigraphic study of Kern et al., [29] gives the anatomic support to the "whole breast" theory of axillary lymphatic drainage, demonstrating a single (91\%) main lymphatic route (the so-called "sentinel lymphatic channel") draining from the rich areolar plexus to the SLN.

If the deep lymphatic drainage leads to the same SLN(s) of the overlying skin, and the common pathway of this superficial plexus is represented by a sentinel lymphatic 
channel connecting the areola to the axilla, the SLN should be considered representative of the whole breast, thus overcoming concerns about the accuracy of the technique in case of MF and MC breast cancers.

Although the existence of a sentinel lymphatic channel has been demonstrated by Kern et al., by using the areolar injection technique [29], the present study gives the first evidence that intradermal radioisotope injections in two different quadrants of the breast give the same SLN visualization in most of the cases. Furthermore, the lymphoscintigrapic study performed in the present series demonstrates in both 2ID and A groups a common final pathway of the superficial lymphatic plexus of the breast toward the axilla in over $90 \%$ of cases, regardless the site of injection.

The common lymphatic pathway of drainage theory for the whole skin envelope of the breast can explain the similar results in term of high accuracy of SLNB in MF and MC cancer reported in this and others series [30-38].

As shown in Table 1, despite of high variability among different studies, all retrospective series [34-36] and multicentric trials $[32,37,38]$ report high accuracy and low false negative rates $(<10 \%)$ of SLNB in MF and MC breast cancer. Tousimis et al., reported a false negative rate of $8 \%$, falling to $0 \%$ once $\mathrm{T} 3$ tumors and intraoperative palpable axillary disease (according to our experience) are excluded [17].

Goyal et al., in the ALMANAC trial retrospectively evaluated the accuracy of the technique in 75 patients, finding a $8.8 \%$ false negative rate. However, SLNB is compared with node sampling instead of a complete AD in most patients and diagnosis of MF-MC cancer was retrospectively obtained only at final pathologic specimens [37].

More recently, a large prospective multi-institutional trial of the Austrian Sentinel Node Study Group was reported by Knauer et al., [38]. In this study the false negative rate of SLNB in $150 \mathrm{MC}$ cancer, 125 of whom underwent AD, was $4.1 \%$, not too far from the one reported in our study.

The prospective monoinstitutional series published in the literature, although performed in small patients populations $[30,31,11,33]$, report excellent results in all but one study [33], where Ozmen et al., show a 33\% false negative rate in MF breast cancers. However, the value of this study is limited by the fact that only MF cancers were enrolled (MC tumors were excluded) and the majority of the cases of this series (18 of 21) had only retrospective, pathologic diagnosis of multifocality.

A possible explanation for this unique unacceptable result, it may be due to technical reasons related to the use of blue dye alone as tracer, injected through peritumoral route, with a very low success rate in SLN identification $(85.7 \%)$. The Authors can only conclude that "SLNB using peritumoral blue-dye injection method is not reliable to be performed in patients with MF disease".

In our experience both areolar (A) and double intradermal (2ID: over the two dominant tumors) injection techniques have demonstrated equally feasible in MF-MC tumors: no differences have been shown in success rate, lymphoscintigraphic anatomy and mean number of SLNs identified. However, 2 ID technique was used mainly for the lymphoscintigraphic study aimed to evaluate the route of lymphatic spreading from different sites of the

Table I: Summary of validation studies of SLNB in MF-MC breast tumors published in the Literature, $1999-2006$

\begin{tabular}{|c|c|c|c|c|c|c|c|}
\hline Author & year & Study & n. pts & Mapping technique & ID \% & FN \% & ACC \% \\
\hline Mertz ${ }^{30}$ & 1999 & Prospective & 16 & $A^{*}$ & 98 & 0 & 100 \\
\hline Schrenk ${ }^{31}$ & 2001 & Prospective & 19 & $A^{\text {blue }+/-} A^{*}$ & 100 & 0 & 100 \\
\hline Kim"l & 2002 & Case reports & 5 & IID* + Tblue & 100 & $\mathrm{nv}$ & $\mathrm{nv}$ \\
\hline Fernandez ${ }^{32}$ & 2002 & Multicentric trial & 53 & $\mathrm{~T}^{*+\text { blue }}$ or ID*+blue or $\mathrm{A}^{*+\text { blue }}$ & 98 & 0 & 100 \\
\hline Ozmen 33 & 2002 & Prospective & $21 \mathrm{MF}$ & Tblue & 85,7 & 33,3 & 77,8 \\
\hline Kumar 34 & 2003 & Retrospective & $59(48 \mathrm{AD})$ & Tblue + I-2ID* & 93,5 & 0 & 100 \\
\hline Tousimis 35 & 2003 & Retrospective & 70 & $\mathrm{~T}^{*+\text { blue }}$ & 95,9 & 8 & 96 \\
\hline Kumar $^{36}$ & 2004 & Retrospective & $10(8 \mathrm{AD})$ & $\mathrm{T}^{*}$ or $\mathrm{A}^{*+\text { blue }}$ & 100 & 0 & 100 \\
\hline Goyal ${ }^{37}$ & 2004 & Multicentric trial & 75 (AD or $S)$ & $\mathrm{T}^{*+\text { blue }}$ & 94,6 & 8,8 & 95,8 \\
\hline Knauer 38 & 2006 & Multicentric trial & $150(125 \mathrm{AD})$ & ns (* or/+blue) & ns & 4,1 & 97,4 \\
\hline Current study & 2006 & Prospective & 31 & $2 \mathrm{ID}^{*}$ or $\mathrm{A}^{*}$ & 100 & 7,1 & 96,8 \\
\hline
\end{tabular}

$A=$ areolar injection of radioisotope $\left(A^{*}\right)$ or blue dye ( $\left.A^{\text {blue }}\right)$

ID = intradermal injection of radioisotope (ID*) or blue dye (IDblue) over one (IID) or two (2ID) neoplastic foci

$\mathrm{T}=$ peritumoral injection of radioisotope $\left(\mathrm{T}^{*}\right)$ or blue dye (Tlue)

ns $=$ non specified

$\mathrm{AD}=$ axillary dissection

$\mathrm{S}=$ lymph node sampling 
breast. Once demonstrated that both pathway converged into one sentinel lymphatic channel in over $90 \%$ of cases, it appears useless and time-consuming to use more than one site of injection (with double dose of radioactivity).

Although a single ID injection over the largest-size lesion has been used in others' experience in case of MF-MC tumors with similar results, areolar injection has the further advantage of being independent from the location of the nodules, which facilitates the procedure, especially in case of non-palpable lesions.

To date our series is the largest monoinstitutional prospective study on SLNB in MF-MC invasive breast cancer and the high accuracy $(96.8 \%)$ is comparable to other differently designed series. Moreover, since surgeons are aware of the possibility of a skip metastasis due to neoplastic obstruction of lymphatic vessels afferent to the true SLN $[16,17]$, during a routine procedure of SLNB a non radioactive but suspicious $\mathrm{LN}$ would be removed and frozen sections could reveal the positive status of axilla. On this basis, if the contraindication to SLNB due to clinically $\mathrm{N}+$ finding is considered both for preoperative and intraoperative diagnosis, the case of skip metastases identified by the surgeon in our study has to be considered excluded from the study, giving a FN rate of $0 \%$, and all sensitivity, negative predictive value and accuracy of $100 \%$.

\section{Conclusion}

Our lymphoscintigraphic study demonstrated that axillary SLN represents the whole breast regardless of tumor location within the parenchyma. $\mathrm{MF}$ and $\mathrm{MC}$ breast cancers should not be considered anymore a contraindication for the SLNB technique. Radioisotope injection through areolar route can be proposed as the best option mapping technique for MF-MC tumors.

\section{References}

I. Schwartz GF, Giuliano AE, Veronesi U: Proceedings of the Consensus Conference on the Role of Sentinel Lymph Node Biopsy in Carcinoma of the Breast, April 19-22, Philadelphia, Pennsylvania. Cancer 2001, 94:2542-2547.

2. Senn HJ, Thurlimann B, Goldhirsch A, Wood WC, Gelber RD, Coates AS: Comments on the St. Gallen Consensus 2003 on the primary therapy of early breast cancer. Breast 2003, I 2:569-582.

3. National Comprehensive Cancer Network: NCCN clinical practice guidelines in oncology . http://www.ncen.org/phisician-gls/f-guide lines.html [Last accessed on]

4. Lyman $G H$, Giuliano $A E$, Somerfield MR, Benson $A B$ 3rd, Bodurka DC, Burstein HJ, Cochran AJ, Cody HS 3rd, Edge SB, Galper S, Hayman JA, Kim TY, Perkins CL, Podoloff DA, Sivasubramaniam VH, Turner RR, Wahl R, Weaver DL, Wolff AC, Winer EP, American Society of Clinical Oncology: American Society of Clinical Oncology Guideline Recommendations for sentinel lymph node biopsy in early-stage breast cancer. J Clin Oncol 2005, 23:7703-7720

5. Kuerer HM, Newman LA: Lymphatic mapping and sentinel lymph node biopsy for breast cancer: developments and resolving controversies. I Clin Oncol 2005, 23:1698-1705.

6. Lagios MD: Multicentricity of breast carcinoma demonstrated by routine correlated serial subgross and radiographic examination. Cancer 1977, 40:1726-1734.
7. Vlastos G, Rubio IT, Mirza NQ, Newman LA, Aurora R, Alderfer I, Buzdar AU, Singletary SE: Impact of multicentricity on clinical outcome in patients with TI-2, N0-I, MO breast cancer. Ann Surg Oncol 2000, 7:581-587.

8. Veronesi U, Paganelli G, Galimberti V, Viale G, Zurrida S, Bedoni M, Costa A, de Cicco C, Geraghty JG, Luini A, Sacchini V, Veronesi P: Sentinel-node biopsy to avoid axillary dissection in breast cancer with clinically negative lymph nodes. Lancet 1997, 349: I864- I867.

9. Borgstein P, Meijer S, Pijpers R, van Diest PJ: Functional lymphatic anatomy for sentinel node biopsy in breast cancer. Echoes from the past and the periareolar blue method. Ann Surg 2000, 232:8I-89.

10. Zavagno G, Rubello D, Franchini Z, Meggiolaro F, Ballarin A, Casara D, Denetto V, Marchet A, Rampin L, Polico C, Nitti D, Mariani G, Italian Study Group on Radioguided Surgery and ImmunoScintigraphy: Axillary sentinel lymph nodes in breast cancer: a single lymphatic pathway drains the entire mammary gland. Eur J Surg Oncol 2005, 3 I:479-484.

II. Jin Kim H, Heerdt AS, Cody HS, Van Zee KJ: Sentinel lymph node drainage in multicentric breast cancer. Breast J 2002, 8:356-36I.

12. Chung $\mathrm{MH}, \mathrm{Ye} \mathrm{W}$, Giuliano $\mathrm{AE}$ : Role of sentinel lymph node dissection in the management of large $(>$ or $=5 \mathrm{~cm})$ invasive breast cancer. Ann Surg Oncol 2001, 8:688-692.

13. Krag DN, Weaver DL, Alex JC, Fairbank JT: Surgical resection and radiolocalization of the sentinel lymph node in breast cancer using a gamma probe. Surg Oncol 1993, 2:335-339.

14. McMasters KM, Wong SL, Martin RC 2nd, Chao C, Tuttle TM, Noyes RD, Carlson DJ, Laidley AL, McGlothin TQ, Ley PB, Brown CM, Glaser RL, Pennington RE, Turk PS, Simpson D, Cerrito PB, Edwards MJ, University of Louisville Breast Cancer Study Group: Dermal injection of radioactive colloid is superior to peritumoral injection for breast cancer sentinel lymph node biopsy: results of a multiinstitutional study. Ann Surg 200I, 233:676-687.

15. Tuttle TM, Colbert M, Christensen R, Ose KJ, Jones T, Wetherille R, Friedman J, Swenson K, McMasters KM: Subareolar injection of $99 \mathrm{mTc}$ facilitates sentinel lymph node identification. Ann Surg Oncol 2002, 9:77-8I.

16. Boolbol SK, Fey JV, Borgen PI, Heerdt AS, Montgomery LL, Paglia M, Petrek JA, Cody HS 3rd, Van Zee KJ: Intradermal isotope injection: a highly accurate method of lymphatic mapping in breast carcinoma. Ann Surg Oncol 200I, 8:20-24.

17. Tousimis E, Van Zee KJ, Fey JV, Hoque LW, Tan LK, Cody HS 3rd, Borgen PI, Montgomery LL: The Accuracy of sentinel lymph node biopsy in multicentric and multifocal invasive breast cancers. J Am Coll Surg 2003, 197:529-535.

18. Goldhirsch A, Glick JH, Gelber RD, Coates AS, Thurlimann B, Senn $\mathrm{HJ}$, Panel members: Panel members: meeting highlights: international expert consensus on the primary therapy of early breast cancer 2005. Ann Oncol 2005, I 6: I569-I583.

19. Purushotham AD, Upponi S, Klevesath MB, Bobrow L, Millar K, Myles JP, Duffy SW: Morbidity after sentinel lymph node biopsy in primary breast cancer: results from a randomized controlled trial. J Clin Oncol 2005, 23:43 I2-432।.

20. Tanis PJ, Nieweg OE, Valdes Olmos RA, Kroon BB: Anatomy and physiology of lymphatic drainage of the breast from the perspective of sentinel node biopsy. I Am Coll Surg 200I, 192:339-409.

21. Sappey PC: Anatomie, phisiologie, patologie des vesseaux lymphatiques consideres chez l'homme et les vertebras Paris: Delahaye and Lecrosnier; 1885.

22. Turner-Warwick RT: The lymphatics of the breast. $B r$ J Surg 1959, 46:574-582

23. Borgstein PJ, Meijer S, Pijpers R: Intradermal blue dye to identify the sentinel lymph node in breast cancer. Lancet 1997, 349: $1668-1669$

24. Klimberg VS, Rubio IT, Henry R, Cowan C, Colvert M, Korourian S: Subareolar versus peritumoral injection for location of sentinel lymph node. Ann Surg 1999, 229:860-864

25. Bauer TW, Spitz FR, Callans LS, Alavi A, Mick R, Weinstein SP, Bedrosian I, Fraker DL, Bauer TL, Czerniecki BJ: Subareolar and peritumoral injection identify similar sentinel nodes for breast cancer. Ann Surg Oncol 2002, 9:169-176.

26. Chagpar A, Martin RC 3rd, Chao C, Wong SL, Edwards MJ, Tuttle T, McMasters KM: Validation of subareolar and periareolar injec- 
tion techniques for breast sentinel lymph node biopsy. Arch Surg 2004, 139:614-618. discussion 618-620

27. Smith LF, Cross MJ, Klimberg VS: Subareolar injection is a better technique for sentinel lymph node biopsy. Am J Surg 2000, 180:434-437. discussion 437-438

28. Tuttle TM: Sentinel lymph node biopsy. Preferred method of axillary staging for breast cancer. Minerva Ginecol 2005, 57:293-303.

29. Kern KA: Lymphoscintigraphic anatomy of sentinel lymphatic channels after subareolar injection of technetium $99 \mathrm{~m}$ sulfur colloid. J Am Coll Surg 200I, 1 93:60I-608.

30. Mertz L, Mathelin C, Marin C, Gairard B, Chenard MP, Brettes JP, Bellocq JP, Constantinesco A: Subareolar injection of $99 \mathrm{~m}-\mathrm{Tc}$ sulfur colloid for sentinel nodes identification in multifocal invasive breast cancer. Bull Cancer 1999, 86:939-945.

31. Schrenk P, Wayand W: Sentinel-node biopsy in axillary lymphnode staging for patients with multicentric breast cancer. Lancet 2001, 357:122.

32. Fernandez K, Swanson M, Verbanac K, Tafra $L$ : Is sentinel lymphadenectomy accurate in multifocal and multicentric breast cancer (abstract). Ann Surg Oncol 2002, 9:SI6-SI7.

33. Ozmen V, Muslumanoglu M, Cabioglu N, Tuzlali S, Ilhan R, Igci A, Kecer M, Bozfakioglu Y, Dagoglu T: Increased false negative rates in sentinel lymph node biopsies in patients with multi-focal breast cancer. Breast Cancer Res Treat 2002, 76:237-244.

34. Kumar R, Jana S, Heiba SI, Dakhel M, Axelrod D, Siegel B, Bernik S, Mills C, Wallack M, Abdel-Dayem HM: Retrospective analysis of sentinel node localization in multifocal, multicentric, palpable, or nonpalpable breast cancer. J Nucl Med 2003, 44:7-10.

35. Tousimis E, Van Zee KJ, Fey JV, Hoque LW, Tan LK, Cody HS 3rd, Borgen PI, Montgomery LL: The accuracy of sentinel lymph node biopsy in multicentric and multifocal invasive breast cancers. J Am Coll Surg 2003, 197:529-535.

36. Kumar R, Potenta $S$, Alavi A: Sentinel lymph node biopsy in multifocal and multicentric breast cancer. J Am Coll Surg 2004, 198:674-675.

37. Goyal A, Newcombe RG, Mansel RE: Sentinel lymph node biopsy in patients with multifocal breast cancer. Eur J Surg Oncol 2004, 30:475-479.

38. Knauer M, Konstantiniuk P, Riegler-Keil M, Wenzl E, Riegler-Keil M, Postlberger S, Reitsamer R, Schrenk P: Multicentric breast cancer as a new indication for sentinel node biopsy - a multiinstitutional validation study. Abstract book of 5th European Breast Cancer Conference. Eur J Cancer 2006, 4:78. (N.II9)
Publish with Bio Med Central and every scientist can read your work free of charge

"BioMed Central will be the most significant development for disseminating the results of biomedical research in our lifetime. "

Sir Paul Nurse, Cancer Research UK

Your research papers will be:

- available free of charge to the entire biomedical community

- peer reviewed and published immediately upon acceptance

- cited in PubMed and archived on PubMed Central

- yours - you keep the copyright
BioMedcentral 